\title{
Pre-mineralisation of starch/polycrapolactone bone tissue engineering scaffolds by a calcium- silicate-based process
}

\author{
A. L. OLIVEIRA ${ }^{1,2 *}$, R. L. REIS ${ }^{1,2}$ \\ ${ }^{1}$ Department of Polymer Engineering, University of Minho, Campus de Gualtar, Guimarães, \\ Portugal \\ ${ }^{2} 3 B^{\prime}$ 's Research Group, Biomaterials, Biodegradables and Biomimetics, University of Minho, \\ Campus de Gualtar, 4710-057, Braga, Portugal \\ E-mail: analeite@dep.uminho.pt
}

\begin{abstract}
This work describes a new methodology to produce bioactive coatings on the surface of starch-based biodegradable polymers or other degradable polymeric biomaterials. As an alternative to the more typical bioactive glass precursors, a calcium silicate gel is being employed as a nucleating agent, for inducing the biomimetic formation of a calciumphosphate (Ca-P) layer. The method has the advantage of being able to coat efficiently both compact materials and porous 3-D architectures aimed at being used on tissue replacement applications and as bone tissue engineering scaffolds. This treatment is also very effective in reducing the incubation periods, being possible to observe the formation of an apatite-like layer, only after $12 \mathrm{~h}$ of immersion in a simulated body fluid (SBF). The apatite coatings formed on the compact surfaces or along the fibres of a fibre mesh scaffold structure made from a starch/polycrapolactone blend (SPCL) were analysed and compared in terms of morphology, chemical composition and structure. After the first days of SBF immersion, the apatite-like films exhibit the typical cauliflower like morphology. With increasing immersion times, these films exhibited a partially amorphous nature and the $\mathrm{Ca} / \mathrm{P}$ ratios became very closer to the value attributed to hydroxyapatite (1.67). It was possible to fully pre-mineralise the SPCL scaffolds and simultaneously to keep the porous morphology of the fibre-bonded scaffold.
\end{abstract}

(C) 2004 Kluwer Academic Publishers

\section{Introduction}

Calcium phosphate (Ca-P) minerals found in natural hard tissues are produced spontaneously in a physiological environment at low temperatures from moderately supersaturated mineralising solutions [1]. To learn from and understand these natural processes and try to apply this knowledge for producing Ca-P coatings chemically and biologically identical to bone apatite has focus the attention of many researchers in the recent years. The socalled biomimetic preparation of calcium phosphate coatings on implant materials has emerged as a new concept $[2,3]$. In the most traditional biomimetic coating routes, the materials are immersed in a simulated body fluid (SBF) with an ion composition similar to the human blood plasma, in order to promote the nucleation and growth of a Ca-P bone-like layer. The basic principle is the formation at the surface (either by chemical bond or adsorption) of certain functional groups that are believed to be favourable for inducing apatite formation [3-5].
This can be achieved by using bioactive silica-based glass particles as nucleating agents that will generate silanol groups $(\mathrm{Si}-\mathrm{OH})$ at the surface of a material [6].

The biomimetic approach is particularly suitable to coat polymeric materials, as it can be carried out at low temperature reaction conditions. In fact, previous studies [7-11] have shown that, when coated with a bone-like apatite layer, biodegradable materials are a promising alternative for a range of bone-related applications. These coatings were already successfully produced, namely by using a sodium silicate gel as a nucleating agent [10], overcoming difficulties like $\mathrm{pH}$ changes, continuous degradation of substrates surface and the complexity of coating 3-D porous architectures. This methodology was also successfully able to reduce the incubation periods for apatite formation. In this study, starch/polycrapolactone blends were selected as substrate. These starch-based biomaterials have already been proposed for applications such as bone replacement/

*Author to whom all correspondence should be addressed. 
fixation $[12,13]$, drug delivery carriers $[14,15]$ or temporary scaffolds for tissue engineering applications $[16,17]$.

It was shown by Oyane et al. [18] that the apatiteforming ability of a silica layer could be remarkably improved by the incorporation of even small amounts of calcium ions into its structure. On the basis of this finding, this group started to use calcium silicate solutions to modify polymeric surfaces in order to induce apatite formation. It is easy to recognise that calcium silicate $\left(\mathrm{CaSiO}_{3}\right)$ can be regarded as a biomaterial, since it is present in the structure of several clinically used bioactive glasses and glass-ceramics (e.g. A/W glass-ceramics) [19-22]. Actually, it is currently being proposed as a bioactive coating by Liu et al. $[23,24]$, that showed that a calcium silicate layer could be produced by plasma spraying wollastonite (a wellestablished calcium silicate) on a titanium substrate. However, due to the high temperatures involved, this methodology is not adequate for coating polymer materials. As referred to above, Oyane et al. [18] have produced a calcium silicate layer at the surface of ethylenevinyl alcohol polymers, by immersing the material in a calcium silicate solution. However, on these works, it was needed to use a silane coupling agent previously to this immersion, in order to modify the chemistry of the surface.

The present work describes an alternative methodology to produce an apatite-like layer, based on the previously developed sodium silicate gel treatment [10]. This methodology was designed by taking advantage of the swelling ability of the used polymers, since they are able to uptake ions that can be favourable for inducing apatite formation. The materials were pre-incubated in a calcium silicate $\left(\mathrm{CaCl}_{2}\right)$ supersaturated solution and then impregnated with a sodium silicate gel. In this way a calcium silicate precursor layer can be precipitated directly at the surface, from the reaction of the absorbed calcium ions with the silicate ions, prior to the immersion in a SBF solution. The as-treated substrates were characterised by scanning electron microscopy (SEM), electron dispersive spectroscopy (EDS), water-uptake measurements and thin film X-ray diffraction (TF-XRD). After immersion in SBF, the formed apatite coatings were characterised by SEM/EDS and TF-XRD analysis.

\section{Materials and methods}

\subsection{Materials}

Natural origin starch-based polymers, exhibit a great potential to be used in a several biomedical applications [6-8, 10,12-15]. In this particular work, the studied material is based on a blend of starch with poly(crapolactone) (SPCL, $30 \mathrm{wt} \%$ in starch), supplied by Novamont, Italy. Compact samples were produced by injection moulding on a Klockner Desma FM-20, using a nozzle temperature of $170^{\circ} \mathrm{C}$. All samples were standard ASTM tensile test bars, with a cross-section of $2 \times 4 \mathrm{~mm}^{2}$, being produced on previously optimised processing conditions. Interconnected fibre meshes of SPCL $\left(5 \times 5 \mathrm{~mm}^{2}\right)$, were also used as substrates in this study. These meshes were prepared by a fibre-bonding technique. The advantageous characteristic features of fibre meshes are a large surface area for cell attachment and a rapid diffusion of nutrients in favour of cell survival and growth [25]. These scaffolds have already being used on bioreactor culture studies leading to very promising results [26].

\subsection{Calcium silicate methodology}

To produce the calcium silicate percussive layers for the formation of an apatite coating, the substrates were submitted to a two-step procedure. The samples were: (i) initially pre-incubated in a $\mathrm{CaCl}_{2}$ supersaturated solution for $24 \mathrm{~h}$ and dried at room temperature; (ii) then, impregnated with a commercially available sodium silicate gel from Sigma-Aldrich $\left(\mathrm{Na}_{2} \mathrm{SiO}_{3} \cdot \mathrm{H}_{2} \mathrm{O}\right.$, containing $\sim 14 \% \mathrm{NaOH}$ and $\sim 27 \% \mathrm{SiO}_{2}, \mathrm{pH} \approx 13$ ) for $24 \mathrm{~h}$ and dried at room temperature. The viscosity of the gel is $6 \times 10^{-2} \mathrm{~Pa} \mathrm{~s}^{-1}$. After this treatment, the samples were washed in distilled water and then dried in a controlled atmosphere $\left(23 \pm 1{ }^{\circ} \mathrm{C} ; 55 \% \mathrm{RH}\right)$.

\subsection{Water-uptake ability}

When implanted, a biodegradable material will inevitably face the presence of the body fluids that will diffuse into the bulk of the polymer as degradation is taking place. Therefore, water-uptake studies are of a great importance to predict its behaviour when immersed in a physiological solution.

The water-uptake ability of compact and porous materials was studied before and after the calcium silicate treatment. For water-uptake measurements all the samples were weighed before being immersed in distilled water (at room temperature) and then every $2 \mathrm{~h}$, during the first $12 \mathrm{~h}$ of immersion. After that period, the weights started to be registered each $24 \mathrm{~h}$, until the end of the experiment time (seven days). The samples were carefully removed from the water-containing flasks and immediately weighed for the determination of the wet weight as a function of the immersion time. Water-uptake is given by:

$$
\text { Water absorbed }=\left[\left(m_{f}-m_{i}\right) / m_{i}\right] * 100
$$

where $m_{i}$ is the initial weight of the sample, and $m_{f}$ is the sample weight after a given time of immersion.

\subsection{Apatite layers formation}

To produce the apatite coatings the calcium silicate precoated substrates were soaked in a SBF solution with an ion concentration nearly equal to human blood plasma (Table I). This solution was prepared by dissolving the different reagent-grades into bi-distilled water and buffered at $\mathrm{pH} 7.4$ with tris(hdroxymethyl)aminomethane $\left(\mathrm{CH}_{2} \mathrm{OH}_{3} \mathrm{CNH}_{2}\right)$ and hydrochloric acid at $37^{\circ} \mathrm{C}$, and was renewed every two days. After one week, the SBF concentration was raised to $1.5 \times$ in order to facilitate the growing of the apatite nuclei and, again renewed every two days. The times of study were an incubation period up to seven days and a growing period up to 30 days. The procedure for apatite formation is schematised in Fig. 1. 


\begin{tabular}{lccccccc}
\hline Solution & \multicolumn{5}{c}{ Concentration/Mm } \\
\cline { 2 - 7 } & $\mathrm{Na}^{+}$ & $\mathrm{K}^{+}$ & $\mathrm{Ca}^{2+}$ & $\mathrm{Mg}^{2+}$ & $\mathrm{Cl}^{-}$ & $\mathrm{HCO}_{3}^{-}$ & $\mathrm{HPO}_{4}^{2-}$ \\
\hline Human plasma & 142.0 & 5.0 & 2.5 & 1.5 & 103.0 & 27.0 & 1.0 \\
SBF 1.0 & 142.0 & 5.0 & 2.5 & 1.5 & 147.8 & 4.2 & 0.5 \\
SBF $1.5 \times$ & 213.0 & 7.5 & 3.8 & 2.6 & 223.0 & 6.3 & 1.0 \\
\hline
\end{tabular}
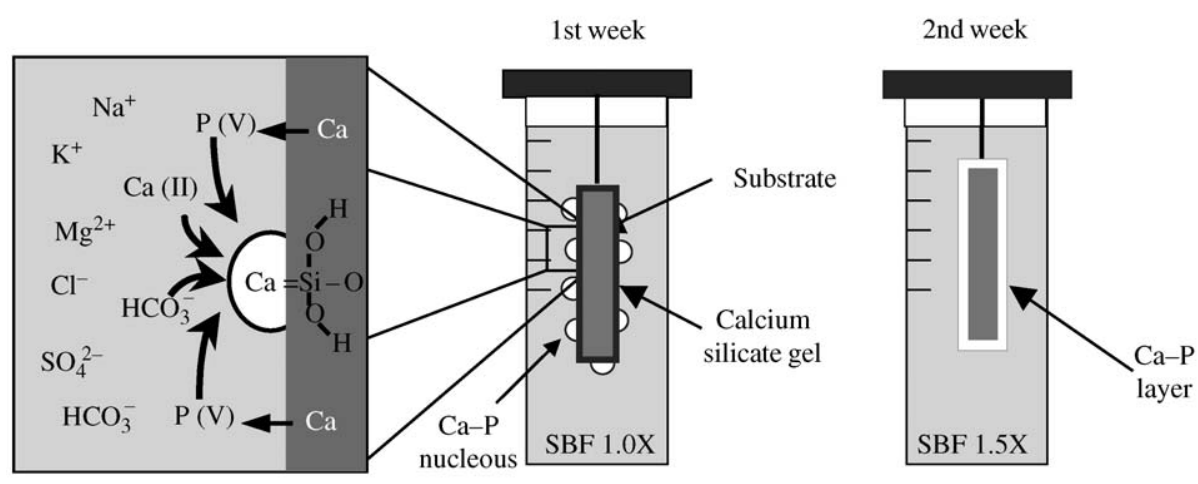

Figure 1 Schematic representation of the calcium silicate biomimetic methodology. Adapted by Reis et al. [6], from the procedure developed by Kokubo et al. [3, 19,28].

\subsection{The SEM, EDS and TF-XRD analysis}

The morphological characterisation was carried out by SEM analysis, in a JEOL JSM $7301 \mathrm{~F}$. All the samples were coated with a thin film of carbon, by ion sputtering, prior to any observation. The electron beam energy was changed between 10 and $12 \mathrm{KeV}$.

A half-quantitative characterisation, using the wellestablished calibration sub-routines for analysing the atomic concentrations was performed by means of EDS, in a Rontec spectrometer for the pre-treated and coated substrates. The amounts of $\mathrm{Ca}, \mathrm{P}, \mathrm{Mg}, \mathrm{K}$ and $\mathrm{Na}$ were quantified after $\mathrm{Ca}-\mathrm{P}$ coating. In the later case, $\mathrm{Ca} / \mathrm{P}$ ratios were calculated. Considering the possibility of $\mathrm{Mg}^{2+}, \mathrm{Na}^{+}$and $\mathrm{K}^{+}$, present in the SBF, substituting the $\mathrm{Ca}^{2+}$ in the crystalline network of the apatite, the following relation was also calculated: $(\mathrm{Ca}+\mathrm{Na}+\mathrm{Mg}+\mathrm{K}) / \mathrm{P}$.

TF-XRD (Philips X'Pert MPD) was used to characterise the crystalline/amorphous nature of the calcium silicate coatings and to identify any crystalline phases present after immersion in SBF. The data collection was performed by $2 \theta$ scan method with $1^{\circ}$ as incident beam angle using $\mathrm{CuK} \alpha \mathrm{X}$-ray line and a scan speed of $0.05^{\circ} /$ $\min$ in $2 \theta$.

\section{Results and discussion}

\subsection{Calcium silicate coating}

Figs. 2 and 3 present the surface morphologies of the compact and porous SPCL before and after the calcium silicate treatment. In Fig. 4 is presented an EDS spectrum of the typical composition of the surface of the materials after the pre-mineralisation treatment.

In Figs. 2 and 3, it is possible to observe that a sodium silicate treatment combined with a previous $\mathrm{CaCl}_{2}$ incubation resulted in the formation of a well-defined coating for both compact and porous structures. By EDS analysis (Fig. 4) it was possible to detect the presence of high amounts of $\mathrm{Ca}$ and $\mathrm{Si}$ in this coating, indicating the formation of a calcium silicate layer. The following simple precipitation reaction for the formation of this layer is taking place: $\mathrm{Na}_{2} \mathrm{SiO}_{3} \rightarrow 2 \mathrm{Na}^{+}+\mathrm{SiO}_{3}^{2-} \Rightarrow$ $\mathrm{Ca}^{2+}+\mathrm{SiO}_{3}^{2-} \rightarrow \mathrm{CaSiO}_{3}$. When comparing the formed layers in terms of morphology for compact and
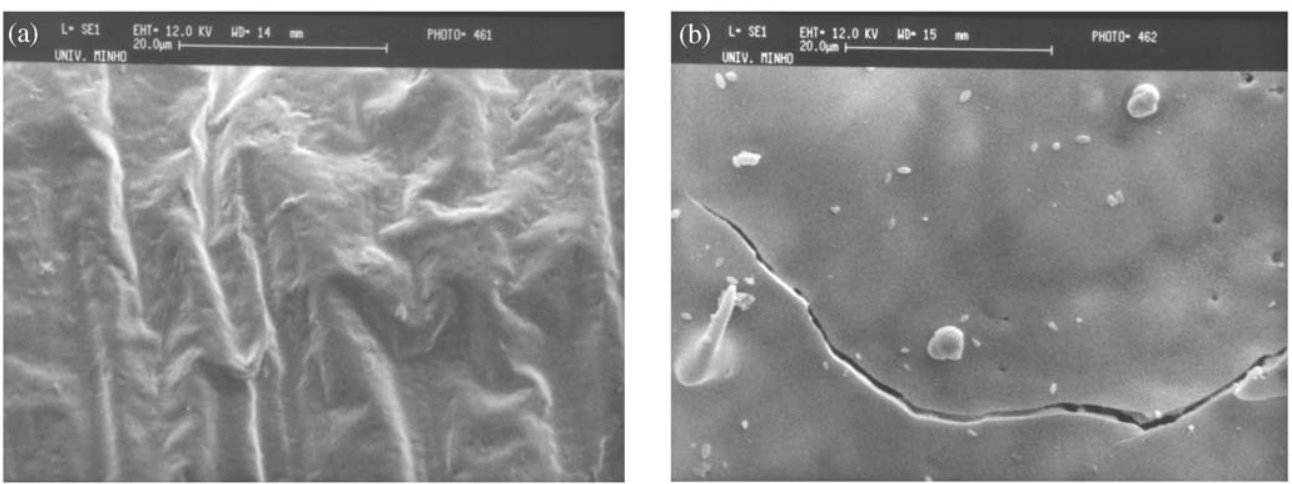

Figure 2 SEM micrographs of compact SPCL: (a) untreated and (b) after calcium silicate treatment. 

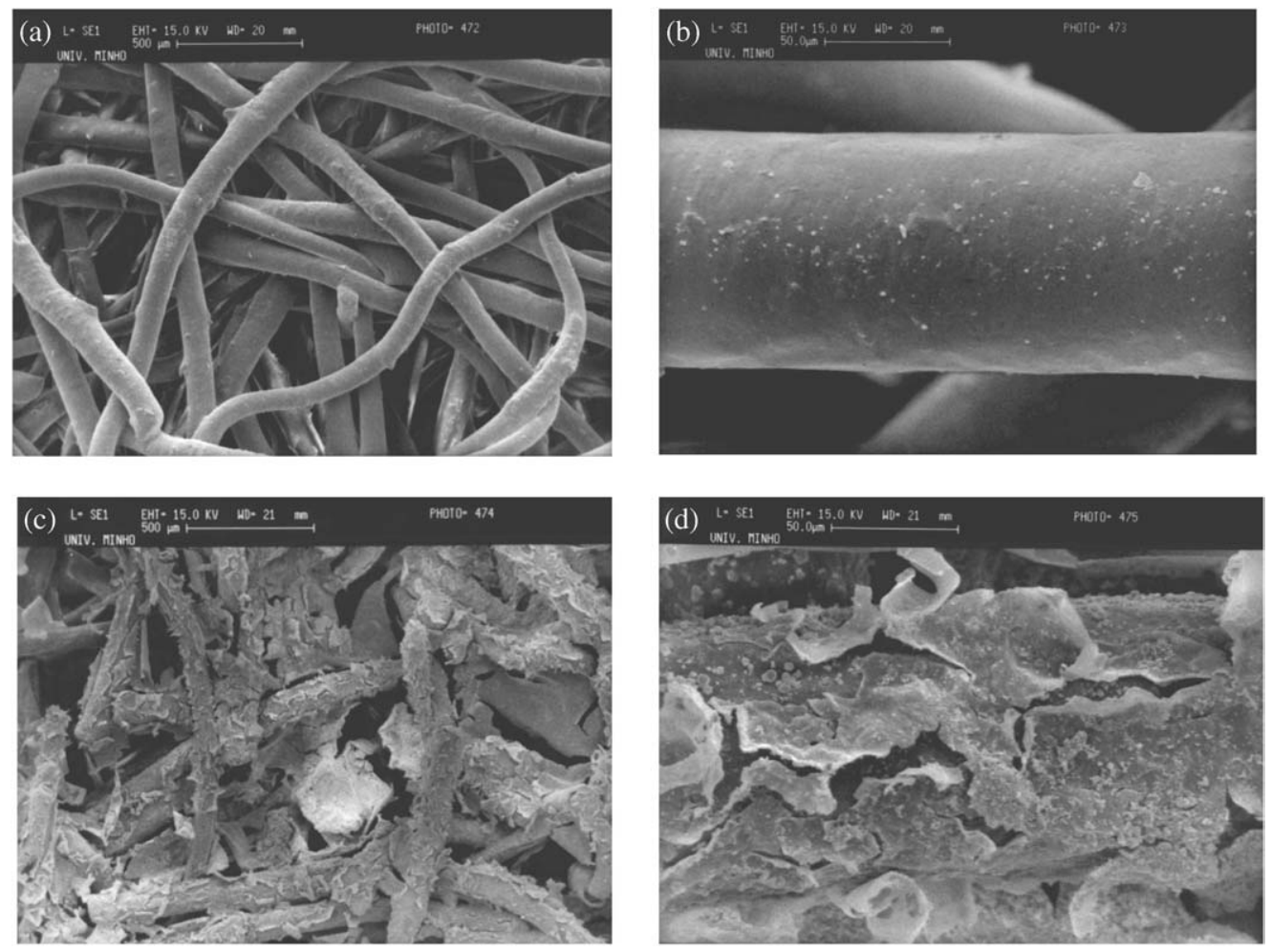

Figure 3 SEM micrographs of porous SPCL: (a) and (b) untreated; (c)and (d) after calcium silicate treatment.

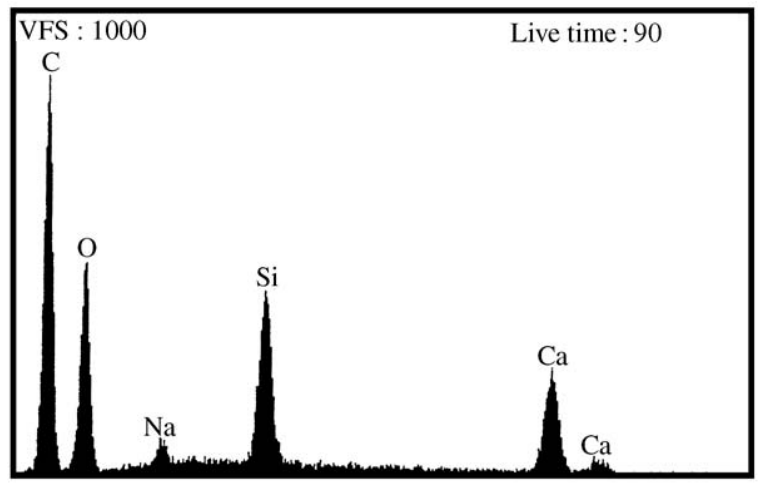

Figure 4 Typical EDS spectrum of SPCL after pre-mineralisation treatment. Example for compact SPCL structure.

porous SPCL, it is possible to observe that in the first case a smooth and stable layer was formed, while for the fibre meshes, a very thick layer was produced that has became fractured. However, even for the later case the coating did not detach from the surface, indicating a good adhesion to the fibre substrate. The differences in the morphologies of the calcium silicates can then be attributed to the different dimensional variations of the polymer structures that occur during the treatment.

Fig. 5 shows the water-uptake versus time for compact (Fig. 5(a)) and porous (Fig. 5(b)) SPCL, untreated and after the calcium silicate treatment.

Only after the first two days of immersion in water, untreated SPCL compact samples uptake $12 \%$ of its weight (Fig. 5(a)), while the fibre meshes are able to uptake $120 \%$ (Fig. 5(b)). Besides uptaking more water to their structure, untreated porous SPCL can achieve the hydration degree earlier than the respective compact materials. This can result from the fact that fibre meshes have a higher specific surface then compact SPCL, allowing for a higher and faster water-uptake. On the other hand, chemical modifications during the different processing routes may play a key role in increasing the amount of polar groups available in case of the porous structure.

Although PCL presents a hydrophobic character, the resulting blend with starch is quite hydrophilic due to the
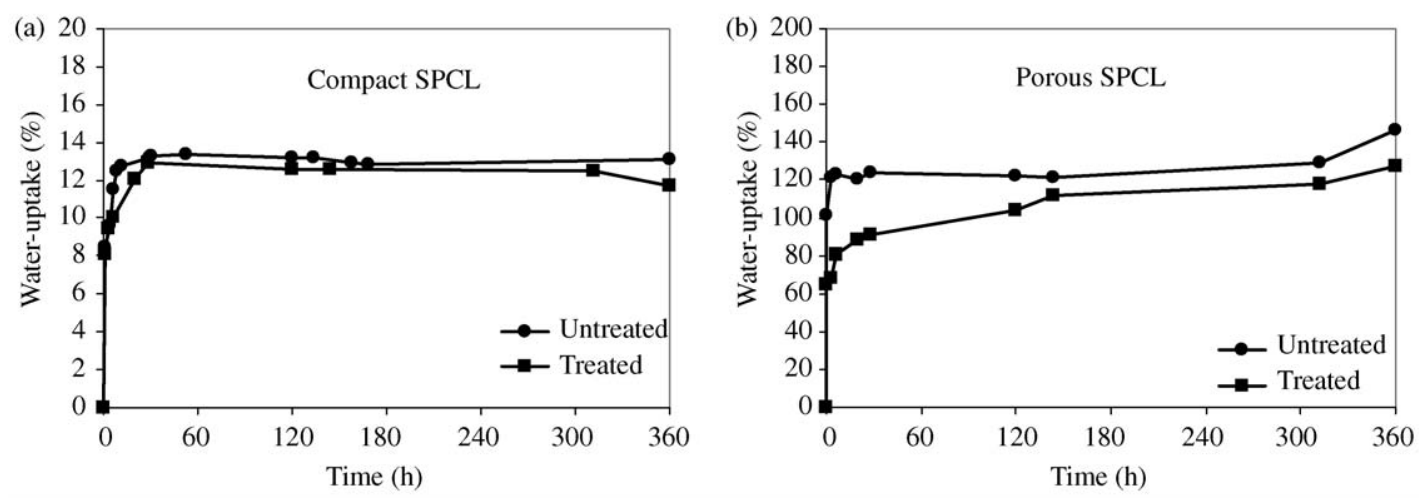

Figure 5 Water-uptake (\%) versus time for untreated and calcium-silicate-treated compact porous SPCL samples. Please note the different scales for each graph. 
presence of starch hydroxyl groups. Therefore, when in solution, SPCL is able to uptake ions into its structure or even to establish a fairly strong bond with these ions. During the pre-incubation in $\mathrm{CaCl}_{2}$ solution, $\mathrm{Ca}^{2+}$ ions were incorporated in the structure. Subsequent sodium silicate gel impregnation has resulted in the formation of a calcium silicate coating. Since the fibre meshes were able to take up a higher amount of ions during the treatment, a thicker calcium phosphate layer was consequently formed. After this pre-mineralisation treatment, the amount of water taken up decreased for both compact and porous SPCL. The presence of calcium and silicate ions either adsorbed in the structure or in the form of a layer acted as a barrier for the absorption of water molecules into the structure; this effect being more accentuated in case of the fibre meshes, where a thicker layer was formed.

\subsection{Apatite formation}

The main aim of the present work was to study the influence of the produced calcium silicate coating on inducing the formation of a bone-like apatite layer. Figs. 6 and 7 present the most relevant SEM micrographs for the compact and porous SPCL coated with a calcium silicate layer after different periods of immersion in SBF solutions.

The calcium-silicate-based methodology has demonstrated to be very effective on forming a continuous and adherent apatite layer on the surface of the compact and porous studied materials. This treatment has produced extremely compact apatite layers when observed at low magnifications but evidence of finer structures at higher magnifications, where needle-like crystals are agglomerated to produce the so-called cauliflower morphology.

For SPCL compact materials, it was possible to observe the formation of the first apatite-like nuclei only after $6 \mathrm{~h}$ of immersion in SBF (Fig. 6(a)). After $12 \mathrm{~h}$ (Fig. 6(b)) those small nuclei have grown to form a welldefined apatite-like coating. The calcium silicate coating methodology was particularly effective in producing an apatite coating in case of SPCL porous structures, showing superior results when compared with the traditional biomimetic methodology. As in compact materials, after $12 \mathrm{~h}$ of immersion in SBF, an apatite layer was formed, that have grown as it is presented in Fig. 7(a) and (b). This layer has covered completely each fibre of the mesh without compromising the porosity of the structure. Therefore, it was possible to maintain the initial porous morphology aimed for tissues engineering applications [26].

It is particularly interesting to compare the evolution of the surface of the fibres before (Fig. 3(a) and (b)) and after the calcium silicate treatment (Fig. 3(c) and (d)) and also after $12 \mathrm{~h}$ of immersion in SBF (Fig. 7(a) and (b)). As previously described, due to the higher amount of calcium ions absorbed into the fibres the calcium silicate generated by immersion in the sodium silicate gel resulted in the formation of an extremely thicker layer that in some cases covered the pores of the mesh. However, during the immersion in SBF with constant renovation of the solution, this layer was dissolved and leached out, leaving the pores open but contributing to the formation of a calcium phosphate layer at the surface of the fibres.

Another important issue to take into consideration concerns the degradation of the starch-based polymers,
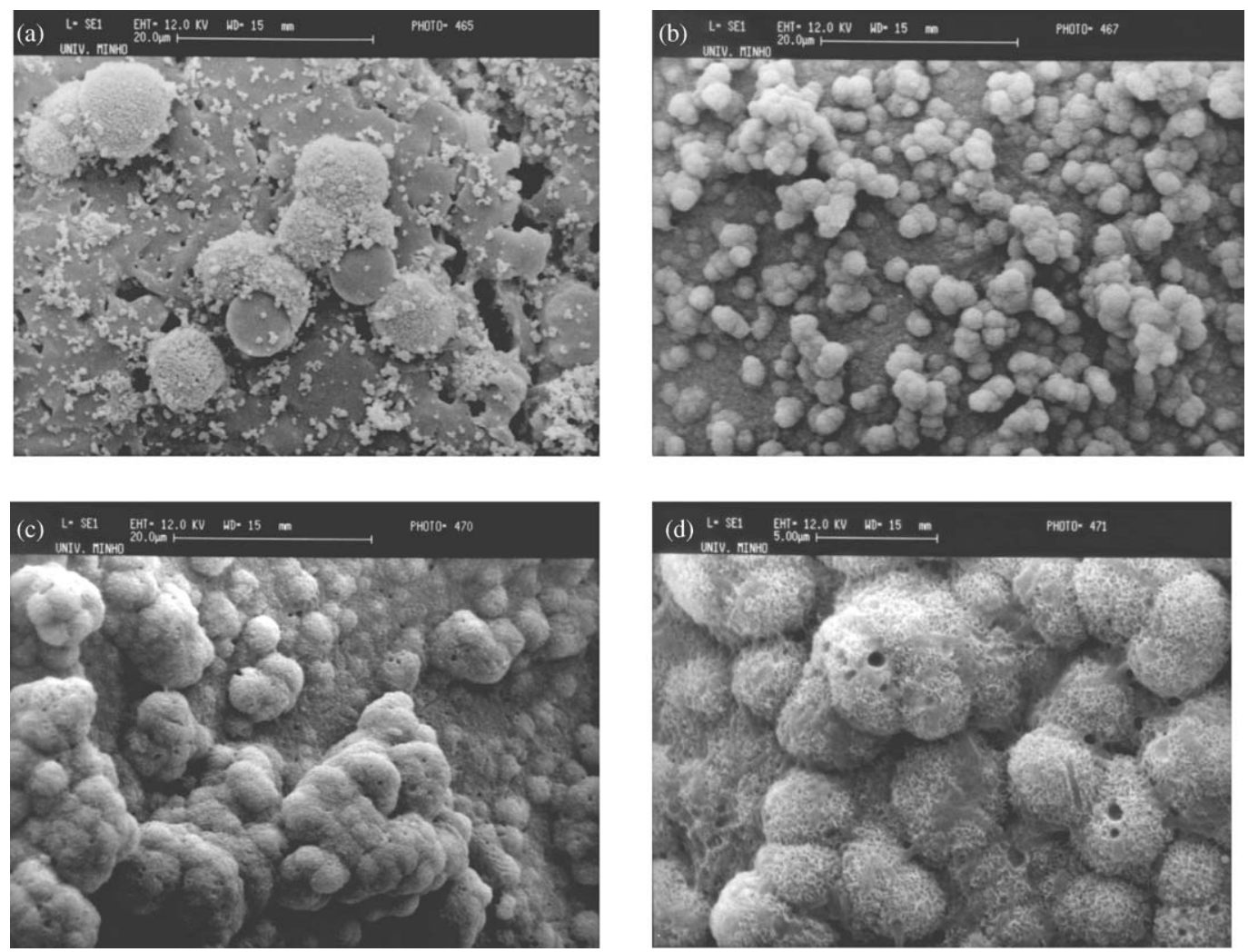

Figure 6 SEM micrographs of compact SPCL coated with a calcium silicate layer and immersed in SBF for (a) $6 \mathrm{~h}$, (b) $12 \mathrm{~h}$ and (c) seven days; (d) magnification of (c). 

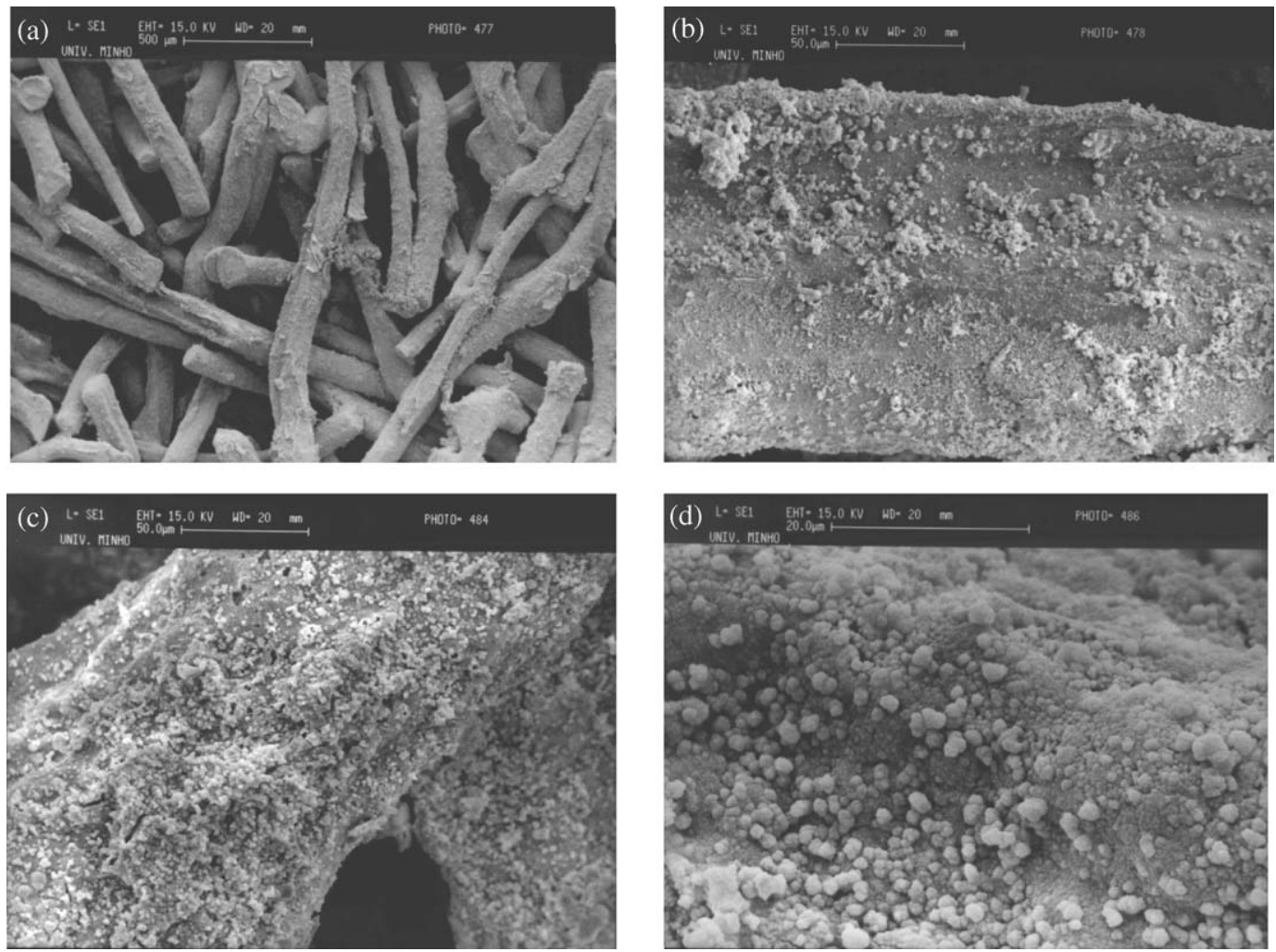

Figure 7 SEM micrographs of SPCL fibre meshes coated with a calcium silicate layer and immersed in SBF for (a) and (b) $12 \mathrm{~h}$; (c) and (d) seven days.

which induces a greater degree of complexity to the reactions since it is continuously changing the composition of the solution adjacent to the interface, namely the $\mathrm{pH}$ and the polymer surface itself. This phenomenon has been previously described by Reis et al. [6]. Nevertheless, the apatite-like layer could be formed in the proposed polymeric structures by means of the herein proposed biomimetic coating route.

Fig. 8 presents the evolution of the $\mathrm{Ca} / \mathrm{P}$ and $(\mathrm{Ca}+\mathrm{Mg}+\mathrm{Na}+\mathrm{K}) / \mathrm{P}$ ratios of the apatites formed on compact (Fig. 8(a)) and porous (Fig. 8(b)) SPCL coated with a calcium silicate layer and after immersion in SBF for different periods up to 30 days.

$\mathrm{The} \mathrm{Ca} / \mathrm{P}$ ratios for the first week of immersion in $\mathrm{SBF}$ tend to be very high (when compared to the value attributed to hydroxylapatite, which is 1.67) and close to the $(\mathrm{Ca}+\mathrm{Mg}+\mathrm{Na}+\mathrm{K}) / \mathrm{P}$ values. This means that there is an excess of $\mathrm{Ca}$ incorporated in the apatite structure that was provided by the $\mathrm{CaSiO}_{3}$ coating initially formed on the surface of the SPCL structures.

For compact SPCL, after $6 \mathrm{~h}$ of immersion in SBF the obtained $\mathrm{Ca} / \mathrm{P}$ ratio was around 2.60. After one week, the $\mathrm{Ca} / \mathrm{P}$ values dropped to 1.71 , which is very close to the typical value of hydroxylapatite. In case of SPCL fibre meshes the initial $\mathrm{Ca} / \mathrm{P}$ values were 5.98 in the first $6 \mathrm{~h}$. This extremely high value can be attributed to the fact that porous structures have a high specific surface area, as compared with compact materials and therefore a higher coated area, which resulted in a high amount of $\mathrm{Ca}$ initially detected by EDS from the $\mathrm{CaSiO}_{3}$ coatings. As in the case of compact SPCL, after seven days of immersion in $\mathrm{SBF} \mathrm{Ca} / \mathrm{P}$ values have decreased to 1.63 , close to the typical value of HA. These results indicate that $\mathrm{PO}_{4}^{3-}$ ions were being incorporated in the structure during the first days of SBF immersion and that a balance was achieved after one week, between the calcium and
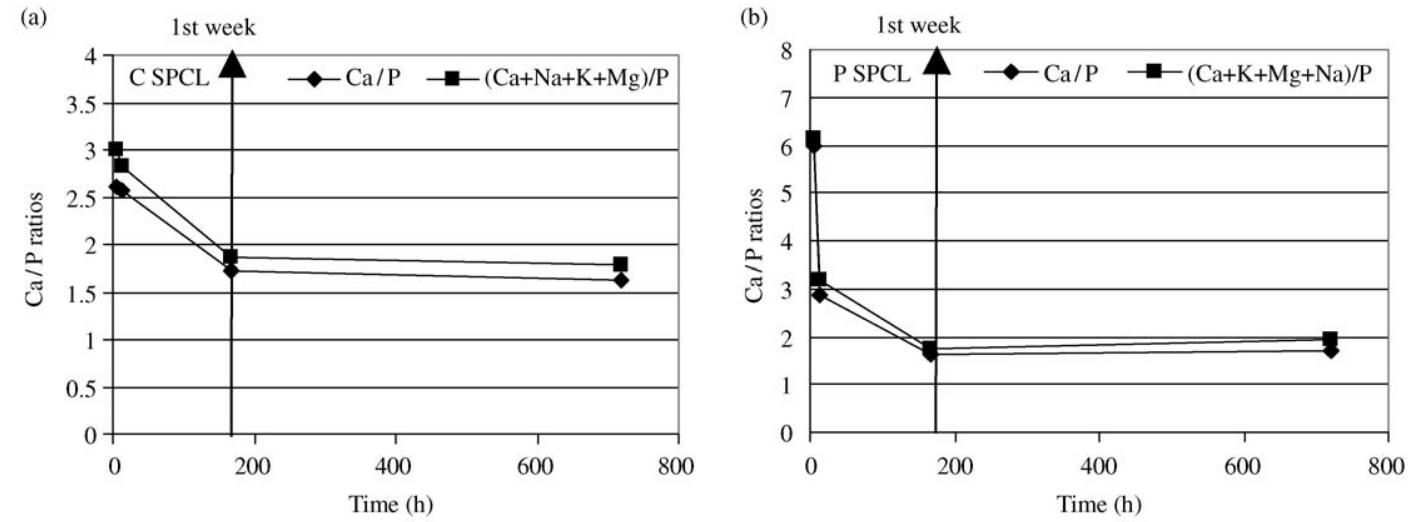

Figure 8 Evolution of $\mathrm{Ca} / \mathrm{P}$ and $(\mathrm{Ca}+\mathrm{Mg}+\mathrm{Na}+\mathrm{K}) / \mathrm{P}$ ratios calculated for the apatites formed on (a) compact and (b) porous $\mathrm{SPCL}$ structures, after different periods of immersion in SBF. Please note the different scales. 
(a)

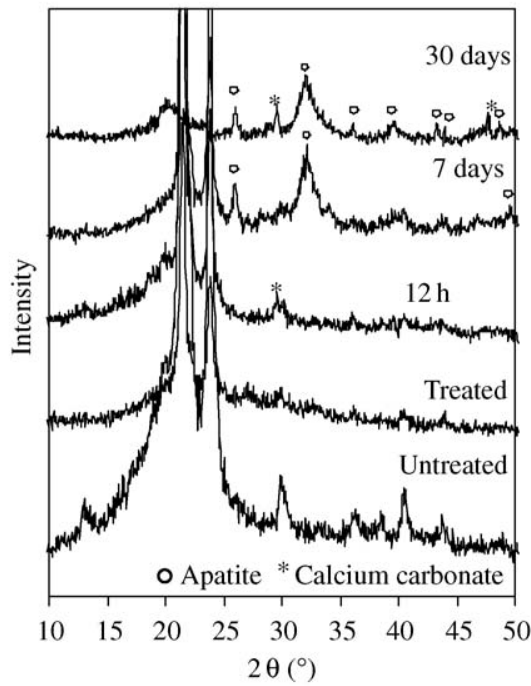

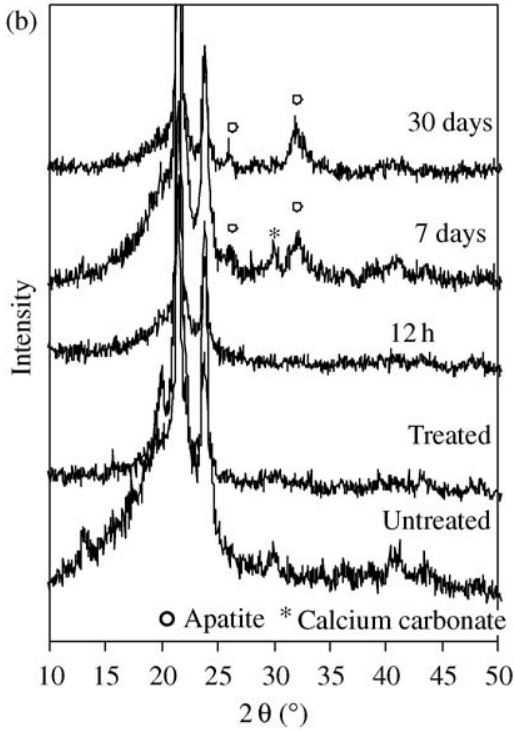

Figure 9 TF-XRD spectra of (a) compact and (b) porous SPCL untreated, coated with a calcium silicate layer and after different periods of immersion in SBF.

phosphate ions to form a coating with $\mathrm{Ca} / \mathrm{P}$ ratios very close to the value of HA. On the other hand, while being dissolved, the calcium silicate layer has been leached out with each renovation of the solution. In fact, by EDS (data not shown), it was no longer possible to detect the presence of $\mathrm{Si}$ after one week.

Fig. 9 presents the TF-XRD patterns of the surface of compact (Fig. 9(a)) and porous (Fig. 9(b)) SPCL, untreated, after calcium silicate treatment and after immersion in SBF for different periods.

The TF-XRD spectra for compact and porous materials show that the pre-calcification treatment has resulted in a totally amorphous calcium silicate coating. For the first incubation periods (up to one week), the apatite formed, as observed by SEM (see Figs. 6 and 7) presented high amounts of calcium (Fig. 8), but was also clearly an amorphous character. For higher immersion times in the SBF solution, the main peaks assigned to hydroxylapatite crystalline phase started to appear both in compact and in porous structures, indicating that a bone-like apatite layer was forming. As is well known, bone apatite also presents a high amorphous content. The mechanism for apatite formation on these surfaces of precipitated calcium silicate coatings is similar to that of $\mathrm{CaO}-\mathrm{SiO}_{2}$-based glasses [19]. This mechanism is schematised in Fig. 1. In this particular case, calcium ions will dissolve from the $\mathrm{CaSiO}_{3}$ coating into the SBF . The mechanism can then be explained by a fast dissolution of the calcium silicate layer into the SBF by releasing $\mathrm{Ca}$ ions from the silicate phase to the solution. Consequently, silanol groups $(\mathrm{Si}-\mathrm{OH})$ will be generated at the surface, acting as favourable sites for the apatite nucleation. On the other hand, the calcium ions released locally (near the surface) will raise the ionic activity product of the apatite, which will increase the kinetics for apatite formation. As a result of this conjugated effect, a large number of apatite nuclei are rapidly formed on the surface. Apatite will subsequently grow spontaneously by consuming the calcium and phosphate ions from the surrounding fluid that is constantly being renovated.
Besides the characteristic peaks, indicating that an apatite is growing from the amorphous coating at the surface of the materials, another crystalline phase was also detected in some of the immersion times for both SPCL compact and porous materials. This phase was assigned to a calcium carbonate crystalline structure. Due to the preliminary nature of these results, this event is yet to be explained. Nevertheless, this particular occurrence, as well as other questions related with the surface chemistry of the materials is worthy of further investigation in detail.

\section{Conclusions}

The calcium silicate treatment resulted in the formation of a clear apatite-like layer on the surface of the SPCL compact and porous structures that could be observed only after $12 \mathrm{~h}$ of immersion in SBF. In case of the fibre meshes, this layer could be also seen inside the pores, covering completely each fibre. It was, in this case, possible to keep the original morphology of the fibre bonded scaffolds. No remarkable differences in composition (EDS) or morphology (SEM) were detected for the apatites formed in compact or porous structures for the longer periods. The $\mathrm{Ca} / \mathrm{P}$ ratios values obtained after one week of immersion in SBF are in the range of stoichiometric HA. This result is consistent with the obtained TF-XRD spectra that, after the same period, show the formation of a partially amorphous $\mathrm{Ca}-\mathrm{P}$ with the crystalline peaks mainly corresponding to hydroxylapatite, approaching bone apatite structure. In some cases, these layers also presented a calcium carbonate crystalline phase that is presently being investigated in detail. This result is very promising for the developing of cancellous bone replacement materials and particularly for pre-mineralisation of bone tissue engineering scaffolds, since the traditional biomimetic methodology is not so effective on coating complex-shaped materials. 


\section{Acknowledgments}

We acknowledge the financial assistance of the Portuguese Foundation for Science and Technology (Ph.D. grant to A. L. Oliveira SFRH/BD/10956/2002 under the POCTI programme). This work was partially supported by FCT Foundation for Science and Technology, through funds from the POCTI and/or FEDER programmes.

\section{References}

1. C. REY, Biomaterials 11 (1990) 13.

2. Y. АвЕ, T. KOK U в O and T. YA MAMURo, J.Mater. Sci. Mater. Med. 1 (1990) 233.

3. M. TANAHASHI, T. YAO, T. KOKUBO, M. MINODA, T. miyamoto, T. NAKAmura and T. yamamuro, J. Am. Ceramic Soc. 77 (1994) 2805.

4. T. KOKUBO, H. M. KIM, M. KAWASHITA and T. NAKAMURA, Z. Kardiol. 90 (2001) 86.

5. M. TANAhAShi and T. MAtSudA, J. Biomed. Mater. Res. 34 (1997) 305.

6. R. L. REIS, A. M. CUNHA, M. H. FERNANDES and R. N. COR REIA, J. Mater. Sci. Mater. Med. 8 (1997) 897.

7. A. L. OLIVEIRA, C. ELVIRA, B. VÁSQUEZ, J. SAN ROMAN and R. L. REIS, ibid. 10 (1999) 827.

8. A. L. OliVEIRA, C. M. ALVES and R. L. REIS, ibid. 13 (2002) 1181 .

9. A. L. Oliveira, M. E. GOMES, P. B. MALAFAyA and R. L. REIS, Bioceramics 15 240-2 (2003) 101.

10. A. L. Oliveira, P. B. MAlafAyA and R. L. Reis, Biomaterials 24 (2003) 2575.

11. A. L. Oliveira, I. B. LeOnor, P. B. Malafaya, C. M. ALVES, H. S. AZEVEDO and R. L. REIS, Bioceramics 15 240-2 (2003) 111.

12. R. L. REIS, A. M. CUNHA, P. S. ALLAN and M. J. BEVIS, Polym. Adv. Technol. 7 (1996) 784.

13. R. L. REIS and A. M. CUNHA, J. Mater. Sci. Mater. Med. 6 (1995) 786.
14. C. ELVIRA, J. F. MANO, J. SAN ROMAN and R. L. REIS, Biomaterials 23 (2002) 1955.

15. C. S. PEREIRA, A. M. CUNHA, R. L. REIS, B. VÁZQUEZ and J. SAN ROMAN, J. Mater. Sci.: Mater. Med. 9 (1998) 825.

16. M. E. GOMES, R. L. REIS, A. M. CUNHA, C. A. BLITTERSWIJK and J. DE. DE BRUIJN, Biomaterials 22 (2001) 883 .

17. P. B. MAlafaya, C. Elvira, A. GAllardo, J. SAN ROMAN and R. L. REIS, J. Biomater. Sci. Polym. Ed. 12 (2001) 1227.

18. A. OYANE, M. KAWASHITA, K. NAKANISHi, T. KOKUBO, M. MINODA, T. MIYAMOTO and T. NAKAMURA, Biomaterials 24 (2003) 1729.

19. T. KOKUBO, S. ITO, Z. T. HUANG, T. HAYASHI, S. SAKKA, T. KITSUGI and T. YAMAMURO, J. Biomed. Mater. Res. 24 (1990) 331.

20. M. TANAHASHI, T. KOKUBO, T. NAKAMURA, Y. KATSURA and M. NAGANO, Biomaterials 17 (1996) 47.

21. K. ONO, T. YAMAMURO, T. NAKAMURA and T. KOKUBO, ibid. 11 (1990) 265

22. K. ONO, T. YAMAMURO, T. NAKAMURA and T. KOKUBO, J. Biomed. Mater. Res. 24 (1990) 11.

23. X. LIU, C. DING and Z. WANG, Biomaterials 22 (2001) 2007.

24. X. LIU, S. TAO and C. DING, ibid. 23 (2002) 963.

25. M. E. GOMES, A. J. SALGADO and R. L. REIS, in "NATO/ ASL Series', edited by R. L. Reis and D. Cohn (Kluwer Press, Dordrecht, 2002) p. 221.

26. M. E. GOMES, V. I. SiKAVitsas, E. BEHRAVESH, R. L. REIS and G. Mikos Antonios, J. Biomed. Mater. Res. 67A (2003) 87.

27. T. KOKUBO, H. KUSHITANI, S. SAKKA, T. KITSUGI and T. YAMAMURO, ibid. 24 (1990) 721.

28. M. TANAHASHI, T. YAO, T. KOKUBO, M. MINODA, T miyamoto, t. nakamura and t. yamamuro, J. Appl. Biomater. 5 (1994) 339.

Received 4 October and accepted 10 October 2003 